\title{
Trabalhando a oralidade na sala de aula por meio do gênero seminário
}

\author{
Exercising orality inside the classroom through the use of the textual \\ genre seminar
}

Raquel Longuinho Lopes de Almeida ${ }^{1}$

Elisete Maria de Carvalho Mesquita²

Marlúcia Maria Alves ${ }^{3}$

\begin{abstract}
Resumo
Estudar os diversos gêneros faz-se necessário no ensino de Língua Portuguesa, uma vez que esse estudo pode contribuir para o desenvolvimento da competência discursiva dos alunos. Nesse contexto, os gêneros orais, por exemplo, são muito importantes, uma vez que por meio deles o aluno tem a oportunidade de explorar os registros da fala formal e informal tanto dentro quanto fora da sala de aula, apropriar-se de características específicas desses gêneros e ver sua produção como prática social. Dentre os gêneros orais que devem ser trabalhados na sala de aula, destacamos o seminário, por esse ser um gênero muito utilizado em diversos contextos escolares e acadêmicos. Muitas vezes, o professor tem dificuldade em trabalhar a oralidade na sala de aula. Por isso, quando há a solicitação para que os alunos apresentem um seminário, não ocorre a orientação adequada e os alunos costumam fazer apenas uma oralização das informações pesquisadas. Considerando a dificuldade do professor em trabalhar a oralidade na sala de aula e do aluno em produzir um seminário, apresentamos uma proposta didática voltada para o ensino-aprendizagem do gênero seminário, desenvolvida em turmas de $9^{\circ}$ ano do Ensino Fundamental. A partir dessa proposta, objetivamos apresentar ao professor uma estratégia para se trabalhar com a oralidade na sala de aula.
\end{abstract}

Palavras-chave: Oralidade. Ensino. Língua portuguesa. Gêneros orais, Seminário.

\footnotetext{
${ }^{1}$ Mestre em Letras pelo Programa de Pós-graduação Mestrado Profissional em Letras (Profletras), da Universidade Federal de Uberlândia (UFU); professora da rede estadual do Estado de Goiás - E-mail: professoraraquellonguinho@gmail.com

${ }^{2}$ Pós-doutora em Linguística e Língua Portuguesa. Professora Associada do Instituto de Letras e Linguística (ILEEL) da Universidade Federal de Uberlândia (UFU) - E-mail: elismcm@gmail.com

3 Professora Associada do Instituto de Letras e Linguística (ILEEL) da Universidade Federal de Uberlândia (UFU) - E-mail: marlucia.alves@gmail.com
} 


\begin{abstract}
Studying the many genres it is necessary in the teaching of Portuguese Language, since this study can contribute to the development of discursive competence of students. In this context, the oral genres, for example, are very important, since through them the student has the opportunity to explore the registers of formal and informal speech both inside and outside the classroom, take ownership of specific features of these genres and view your production as social practice. Among the oral genres that should be worked out in the classroom, we highlight the seminar, that being a genre widely used in school and academic contexts. Often, the teacher has difficulty in working the orality in the classroom. So when there is a request for students to present a seminar, not proper orientation occurs and the students usually do only an 'oralização' of information searched. Considering the difficulty of the teacher in working the orality in the classroom and the student to produce a seminar, we present a didactic proposal focused on the teaching and learning of the seminar genre, developed in 9th grade classes of Elementary School. From this proposal, we aimed to present to the teacher a strategy for working with the orality in the classroom.
\end{abstract}

Keywords: Orality. Teaching. Portuguese. Oral textual genres. Seminar.

\title{
Introdução
}

Durante muito tempo o ensino de Língua Portuguesa esteve voltado para o ensino descontextualizado da língua, centrando-se apenas na gramática, sem se preocupar com o desenvolvimento da competência comunicativa do aluno.

Essa situação começou a mudar a partir do momento em que estudiosos como Geraldi (1984), por exemplo, começaram a discutir sobre as concepções de linguagem e o modo como elas podem influenciar positiva ou negativamente no processo de ensino-aprendizagem de uma lingua. Essa discussão contribuiu para que o ensino de Língua Portuguesa começasse a ser concebido como uma totalidade da qual fazem parte a leitura, a produção de textos e a análise linguística. Posteriormente no final da década de 1990 foram publicados os Parâmetros Curriculares Nacionais - PCN (BRASIL, 1997; 1998) pelo governo federal. Esse documento, direcionado à Educação Básica, defende as práticas sociais (interação) no ensino de Língua Portuguesa. De acordo com essa perspectiva, o discurso se manifesta por 
meio de textos e todo texto é organizado dentro de um determinado gênero, pois este centra-se no desenvolvimento da competência comunicativa do aluno.

Partindo de uma visão interacionista da linguagem, os Parâmetros Curriculares Nacionais de Lingua Portuguesa - PCNLP (BRASIL, 1997; 1998) preconizam que o ensino da Língua Portuguesa deve centrar-se em práticas significativas e contextualizadas, em que o uso da lingua oral, escrita, análise e reflexão sobre a língua sejam trabalhos essenciais no processo de aprendizagem, a fim de que o aluno desenvolva as quatro habilidades linguísticas básicas: falar, escutar, ler e escrever. Esse trabalho, para surtir os efeitos desejados, deve ser realizado a partir do contato do aluno com os diferentes gêneros que circulam na nossa sociedade.

Considerando os benefícios de um trabalho pautado no uso dos gêneros na sala de aula, especialmente no que diz respeito aos gêneros orais, podemos dizer que é extremamente importante que a oralidade seja trabalhada na sala de aula por meio desses gêneros, por exemplo, pois o ser humano possui a necessidade de se expressar, oralmente sobretudo, o que se dá por meio da utilização de um determinado gênero.

Acreditamos que seja papel da escola fazer com que o aluno pratique a oralidade e produza gêneros orais formais/informais e especialmente que ele desenvolva sua competência comunicativa nas aulas de Língua Portuguesa. Porém, sabemos que, quando comparada à escrita, a oralidade é menos abordada na sala de aula. Se levarmos em conta a participação do professor e do aluno nesse processo, podemos dizer que, de um lado, isso acontece, muitas vezes, por falta de conhecimento do professor no que diz respeito às especificidades da oralidade. Muitos professores acreditam que trabalhar oralidade é apenas oralizar textos ou apenas conversar/dialogar com seus alunos na sala de aula. Do outro lado, falta ao aluno, muitas vezes, o conhecimento necessário para a produção do gênero. Desse modo, quando lhe é solicitada uma apresentação de um seminário, ele costuma não ter noção de como usar a oralidade. Essa realidade nos leva à conclusão de que o seminário não costuma ser tomado como um gênero oral a ser ensinado 
durante as aulas de Língua Portuguesa, o que resulta em apresentações que nem sempre satisfazem nem aos professores nem aos próprios alunos. Nesse contexto, muitas vezes desfavorável, o uso da oralidade não acontece de maneira eficaz. Notamos, portanto, que o trabalho com a prática de oralidade deve ser realizado na sala de aula para que os alunos saibam como utilizá-la dentro e fora da sala de aula, uma vez que ela é importante como prática social e sobretudo em seu registro formal da língua e na produção de gêneros orais; além de se fazerem necessárias discussões e propostas sobre a relação entre oralidade e ensino.

Tendo em conta a riqueza e vantagens de um trabalho centrado na oralidade é que decidimos estabelecer um diálogo com o professor de Língua Portuguesa, visando a apresentar a ele uma maneira de se valorizar a oralidade na sala de aula. Para isso, escolhemos o gênero seminário.

A escolha do seminário como objeto de ensino se deve ao fato de esse gênero ser muito utilizado em diversos contextos escolares, educacionais e acadêmicos. Seu uso na escola geralmente ocorre quando um professor de qualquer disciplina quer avaliar o nível de conhecimento dos alunos sobre um determinado assunto. Acreditamos, portanto, que esse é um ótimo gênero para se trabalhar efetivamente a oralidade nas aulas de Língua Portuguesa.

Visando a atingir o objetivo proposto, dividimos este artigo em três seções. Na primeira, estabelecemos uma discussão a respeito da oralidade na sala de aula. Na segunda, destacamos a inserção do seminário nas aulas de Língua Portuguesa como forma de contribuir para que o aluno seja bemsucedido com relação ao uso da língua em situações mais monitoradas, mais formais. Na terceira seção, objetivando dialogar com o colega-professor, apresentamos uma proposta didática ${ }^{4}$ com enfoque no gênero seminário.

\footnotetext{
${ }^{4}$ Essa proposta, na íntegra, constitui a dissertação, intitulada Seminário em sala de aula: teoria, análise e intervenção, desenvolvida no Programa de Pós-graduação Mestrado Profissional em Letras da UFU (Profletras).
} 


\section{A prática da oralidade e a produção de gêneros orais}

Para Bakhtin (1997), lingua e gênero estão intimamente relacionados. Tanto é verdade que só nos comunicamos, falamos e escrevemos por meio de gêneros discursivos, que estão no nosso cotidiano de sujeitos falantes, que possuímos um infindável repertório de gêneros, muitas vezes, usados inconscientemente. Até nas conversas mais informais, por exemplo, o discurso é moldado pelo gênero em uso.

Segundo o autor, cada esfera comunicativa abarca determinados gêneros, que podem ser identificados a partir de suas especificidades. Desse modo, as funções (científica, técnica, ideológica, oficial, cotidiana), específicas para cada uma das esferas da comunicação verbal, geram um dado gênero, ou seja, um dado tipo de enunciado, relativamente estável do ponto de vista temático, composicional e estilístico. Em outras palavras, os enunciados refletem as condições específicas de produção e as finalidades de cada esfera comunicativa, não apenas seu conteúdo temático, seu estilo verbal, ou seja, a seleção de recursos da lingua, recursos gramaticais, fraseológicos e lexicais, mas há também uma estrutura composicional que o forma. Esse "tripé", que constitui os gêneros, segundo Bakhtin, deve ser observado quando se lida com determinado gênero.

Levando em consideração a relevância de cada um desses aspectos para a identidade dos gêneros, entendemos que não há como negar a importância do trabalho voltado para o uso da língua, ou seja, para situações de interação verbal produzidas em diferentes circunstâncias. Entendemos, então, que estudar os gêneros é, também, estudar diferentes aspectos da oralidade, uma vez que ela faz parte de muitas práticas sociais e do cotidiano das pessoas. Segundo Marcuschi (2008, p. 25), a oralidade seria "uma prática social interativa para fins comunicativos que se apresenta sob variadas formas ou gêneros textuais fundados na realidade sonora". Como o autor nos mostra, há interação entre interlocutores e um tópico discursivo (assunto) é desenvolvido para uma determinada prática social. 
É com a modalidade falada que as pessoas fazem negociações, aprendem conteúdos, manifestam suas crenças, procuram convencer outros dessas crenças, transmitem sua própria cultura, entre muitos outros usos a serviço de uma necessidade comunicativa na sociedade, além de ser usada para nos mostrarmos uns aos outros e para construirmos uma imagem de nós mesmos (FREITAS, 2006). Além disso, entendemos que é preciso considerar que a fala é uma modalidade aprendida antes da escrita e fora da escola, sempre utilizada em diferentes práticas sociais, que faz grande diferença para a inserção social de um indivíduo e que deve ser aperfeiçoada em sala de aula.

Para Goulart (2005), a oralidade tem aplicação direta em vários campos da vida social do usuário da língua, no trabalho, nas relações interpessoais e na política. O falante deve adequar língua falada e escrita conforme a necessidade, mais formal ou menos formal, por exemplo, a fim de atender suas necessidades discursivas. É na escola que o aluno poderá ter acesso à língua em suas distintas manifestações.

Pensando na relevância de um trabalho que priorize a oralidade, podemos dizer que a sala de aula deve ser o lugar do uso da fala, de maneira formal e informal. E além da fala, a oralidade pode materializar-se, portanto, por meio de textos, aos quais nomeamos de gêneros orais, que são extremamente importantes para o ensino de língua materna.

É importante termos em mente que a oralidade é diferente de modalidade falada, afinal oralidade é uma prática social que usa a fala como apoio (MARCUSCHI, 2010). Esta diferença é importante para não confundir o trabalho na sala de aula, pois, muitas vezes o professor trabalha apenas a fala e não a oralidade. Outra reflexão importante é sobre a oralização de textos, por exemplo, a leitura em voz alta de textos escritos, que muitos professores pensam também estar trabalhando com a oralidade. A oralidade acontece efetivamente quando o aluno percebe que produziu gêneros orais ou a fala a serviço de uma prática social, como ocorre no seminário, que o aluno produz. 
Para definir oralidade, partiremos das ideias de Marcuschi (2010) que afirma que a fala seria uma forma de produção textual-discursiva para fins comunicativos; não há a necessidade de uma tecnologia além do aparato disponível pelo próprio ser humano, ou seja, o uso da língua na sua forma de sons sistematicamente articulados e significativos, bem como os aspectos prosódicos e série de recursos expressivos de outras ordens, tais como a gestualidade, os movimentos do corpo e a mímica, por exemplo.

Com relação ao ensino da oralidade, Antunes (2003) também entende que o trabalho dos professores com a oralidade na sala de aula nem sempre é eficaz o suficiente para que os alunos desenvolvam sua competência comunicativa. Por mais dificil que seja acreditar, alguns professores ainda acreditam que os usos da língua falada, tão presentes no cotidiano do aluno, não precisam ser trabalhados nas aulas. Além disso, a oralidade é reduzida à produção de gêneros orais informais, como a conversa, por exemplo, nos quais predominam os registros informais da lingua. Essa afirmação reforça a ideia de que muitos professores pensam apenas que a prática escolar de ler em voz alta seja usar a oralidade. Esse e outros equívocos nos levam a concluir que é, então, papel da escola desenvolver um trabalho voltado para a oralidade, embora saibamos que, nas escolas brasileiras, os professores prefiram trabalhar com os gêneros escritos, com afirma Goulart (2005).

Os PCNLP (BRASIL, 1997; 1998) também afirmam que há deficiência no que diz respeito ao trabalho com a oralidade na sala de aula e que não há preocupação em se ensinar a estrutura textual e a funcionalidade dos gêneros orais na escola. Esse documento entende que essa falta de preocupação faz com que os alunos se apropriem somente da estrutura dos gêneros orais, o que tem como consequência a ineficiência do estudo dessas entidades, uma vez que são inúmeras as situações fora do ambiente escolar em que os alunos podem necessitar dominar as especificidades dos gêneros orais utilizados em situações mais formais e isso só se dará de forma satisfatória se a escola tomar para si a responsabilidade de promover essa abordagem. Os PCNLP também consideram que a competência linguística e 
discursiva que o aluno traz, quando ingressa na escola, possibilita as interações sociais do cotidiano. (BRASIL, 1998).

Por isso, os PCNLP (BRASIL, 1998) defendem o ensino da lingua oral como forma de possibilitar o acesso à língua mais formal.

\begin{abstract}
Ensinar língua oral deve significar para a escola possibilitar acesso a usos da linguagem mais formalizados e convencionais, que exijam controle mais consciente e voluntário da enunciação, tendo em vista a importância que o domínio da palavra pública tem no exercício da cidadania (BRASIL, 1998, p. 67).
\end{abstract}

Considerando tanto as diretrizes dos PCNLP quanto a realidade relatada por diversos pesquisadores, nos perguntamos: qual seria o papel da escola no ensino da oralidade? Como contribuir para que os alunos aperfeiçoem sua capacidade de expressão na língua falada, apropriando-se da multimodalidade pertencente à oralidade? Segundo Cavalcante e Melo (2006, p.183), "um dos papeis da escola é fazer com que os alunos sejam expostos às diversas atividades sociais e de cidadania". Nesse sentido, o ensino da oralidade deve fazer parte das atividades programadas pela escola, pois isso poderá ajudar o aluno a se apropriar de diversas práticas sociais usando a oralidade.

[...] um trabalho consistente com a oralidade em sala de aula não diz respeito a ensinar o aluno a falar, nem simplesmente propor apenas que o aluno 'converse com o outro' a respeito de um assunto qualquer. Trata-se de identificar, refletir e utilizar a riqueza e variedade de usos da língua na modalidade oral. (DOLZ; SCHNEUWLY; HALLER, 2011 [2004]).

As práticas de oralidade na sala de aula poderão ocorrer por meio dos gêneros orais. Segundo Marcuschi (2008), o estudo da classificação dos gêneros orais é recente. Eles são textos sociointerativos que se constroem na interação comunicativa. O autor entende que os gêneros orais pressupõem conhecimentos globais e marcas linguísticas que os identificam, além de processadores que ativam sua produção, inserindo-se nas diversas atividades humanas. Essas características apontam para a necessidade de o ensino explorar mais o estudo com gêneros orais, sejam eles formais ou não. 
Os gêneros orais formais apresentam características estruturais, linguísticas e discursivas específicas que se confrontam com os gêneros orais cotidianos, fator que possibilita ao estudante dominar formas mais institucionalizadas da lingua.

O trabalho com os gêneros orais formais não exclui a leitura ou a escrita, ou seja, a leitura e a escrita prévia sobre o tema, anterior à oralidade, são habilidades exercidas como planejamento prévio que direciona e organiza o processo posterior: a oralidade. São habilidades lexicais, gramaticais, linguísticas e comunicativas desenvolvidas por meio de textos orais, porém, a maior contribuição está na aquisição da posição e na postura diante do outro. Os gêneros orais são muito importantes para o desenvolvimento das competências comunicativas do aluno, tendo em vista que os gêneros de maneira geral são objetos relevantes para o ensino de Lingua Portuguesa.

Toda introdução de um gênero na escola é resultado, portanto, de uma escolha didática que apresenta dois objetivos: o domínio de um gênero e a inserção do aluno em situações comunicativas para o uso desse gênero no processo de ensino-aprendizagem. Eles colaboram para o desenvolvimento da linguagem e funcionam como objeto e instrumento de trabalho para professores. Por isso, não há como negar que os gêneros constituem uma prática social relevante dentro e fora da escola.

\section{0 gênero seminário}

O seminário é um gênero a partir do qual é possivel trabalhar as práticas de oralidade, não sendo, portanto, destinado, exclusivamente, à área de Língua Portuguesa, mas sim a todas as disciplinas que compõem a estrutura curricular da escola. Isso significa que o seminário tem de ter objetivos e/ou finalidades bem definidos, o que extrapola uma mera "exposição" informal. É um gênero escolar muito solicitado por professores de Ensino Fundamental, Médio e até mesmo Superior (BRAIT; ROJO, 2002). Ele permite a construção conjunta do conhecimento, promovendo uma aula 
menos centralizada no professor e com menor tendência de que os alunos assumam um papel de ouvintes passivos como normalmente acontece numa aula expositiva tradicional, além de despertar mais interesse do colega em ouvir o que os demais colegas têm a dizer. É como afirmam Brait e Rojo,

\begin{abstract}
ao sugerir um tema para ser discutido e apresentado sob a forma de seminário, o professor está propondo uma interação ativa entre ele e os alunos e as fontes de conhecimento e entre os alunos realizadores e os receptores. O que está em jogo não é apenas um tema, mas uma forma de composição e um estilo específico de tratamento desse tema, de maneira que os diferentes resultados sejam produtivos (BRAIT; ROJO, 2002, p. 1).
\end{abstract}

O seminário representa um instrumento pedagógico privilegiado para aquisição de conhecimento de quem ouve e, sobretudo, para quem o prepara e o apresenta, ou seja, é um instrumento para aprender conteúdos diversificados, mas estruturados graças ao enquadramento viabilizado pelo gênero.

A estrutura composicional do seminário é muito parecida com a estrutura da exposição oral, gênero estudado por Dolz, Pietro e Schneuwly (2004), apresentando dimensões ensináveis como: a situação de comunicação (reúne alunos que fazem uma exposição a um público) sobre um tema, sendo que o aluno estará na posição de especialista; organização interna: 1) uma fase de abertura, 2) introdução ao tema, 3) apresentação do plano da exposição, 4) o desenvolvimento e encadeamento dos diferentes subtemas, 5) uma fase de recapitulação e síntese, 6) a conclusão, 7) o encerramento.

Desta forma, o seminário apresenta várias características: linguísticas (coesão temática, sinalizações do desenvolvimento do texto); introdução de exemplos, reformulações, preparação e oralização de notas. Os objetivos da exposição oral são: consciência da situação de comunicação; exploração de fontes de informação; estruturação de uma exposição.

Antes da apresentação, existe a fase de preparação. Segundo Vieira (2005), essa é uma fase extremamente importante, pois ela assegurará que a 
apresentação e a discussão não sejam superficiais. O aluno, nesse momento, poderá ter a compreensão dos objetivos e do tema proposto. Ainda nessa etapa, cabe ao professor orientar e ajudar os alunos com a bibliografia, localização das fontes de pesquisa, a sugestão das questões centrais e métodos de análise mais adequados, a delimitação de tópicos para análise e discussão, o cumprimento do cronograma estabelecido para o trabalho e, ainda, sugerir a organização física da sala de aula, de modo que favoreça a socialização do conhecimento.

O aluno ou grupo, por sua vez, a partir da escolha do tema, irá buscar as informações em fontes diversas, selecioná-las, fazer uma síntese do material e estudá-lo com profundidade, organizar a apresentação em termos de utilização de recursos materiais e didáticos, além de negociar os papéis de relatores e comentaristas entre os representantes do grupo.

Entendemos que o seminário se configura, portanto, como um gênero muito importante para a aquisição de conhecimentos que podem interessar aos alunos. Assim, em consonância com Vieira (2005), entendemos que o seminário é um evento comunicativo e de letramento e também um instrumento importante de interação e desenvolvimento de atividades de leitura, exposição, escrita e debate, equivalendo as duas modalidades da língua na produção do evento comunicativo.

De acordo com Vieira (2005), nos seminários, observa-se a construção de significados pautados na escrita, na oralidade, nos gestos, no tom da voz, na música, nas imagens, dos movimentos corporais e de tantos outros elementos que terminam por configurá-lo como uma produção multimodal. Daí a necessidade de considerar os múltiplos letramentos neles envolvidos, como o letramento escolar tradicional o letramento tecnológico e o letramento visual.

A autora defende que a prática do seminário contribui para o estabelecimento, na sala de aula, de um ambiente propício ao ensino e à aprendizagem de multiletramentos. Ele contribui para uma participação mais completa do aluno tanto na escola como fora dela, ampliando suas 
possibilidades de interação com outros protagonistas sociais e o desenvolvimento de novos letramentos.

Por meio do seminário, é possivel trabalhar a oralidade de diversas formas, uma vez que ele: i) permite que o aluno faça uma retextualização, ou seja, transforme da modalidade escrita (textos escritos relacionados ao tema proposto) em uma discussão com seu grupo para a modalidade falada (gênero oral seminário); ii) explora outros recursos tecnológicos e midiáticos (projetor, figuras, gráficos) para motivar sua oralidade; iii) utiliza outros gêneros orais em sua elaboração (debate e entrevista, por exemplo) e v) trabalha, sobretudo, a oralidade como prática social em sala de aula em uma situação real do uso da língua.

Vejamos a seguir como promover o uso da oralidade por meio do seminário na sala de aula.

\section{Uma proposta para se trabalhar o gênero seminário na sala de aula}

Objetivando dialogar com o professor de Lingua Portuguesa no que diz respeito ao trabalho tanto com a oralidade quanto com o gênero seminário, apresentamos uma proposta didática ${ }^{5}$ que foi desenvolvida com alunos de uma turma de 9o ano do Ensino Fundamenta. Para a concepção e aplicação dessa proposta, contamos com a valiosa contribuição de dois outros gêneros orais: o debate e a entrevista.

A opção pela adoção e aplicação dessa proposta didática se deve ao fato de entendermos que essa é uma boa estratégia de ensino-aprendizagem, pois pode promover uma relação de interação em que a produção inicial direciona as atividades nos módulos e a realização de uma produção final do gênero, o que pode diminuir as dificuldades enfrentadas pelos alunos no momento de produzirem um seminário.

\footnotetext{
${ }^{5}$ Esta proposta didática foi concebida a partir do "modelo" de sequência didática (DOLZ; NOVERRAZ; SCHNEUWLY, 2004). Desse modo, embora dela constem uma situação inicial, módulos e a produção final, não é possível reconhecer o esquema exatamente como proposto pelos autores.
} 
Para o desenvolvimento da proposta, buscamos apoio nas ideias de Bakhtin (1997), principalmente no que diz respeito aos elementos que, segundo esse autor, são constitutivos dos gêneros, quais sejam: conteúdo temático, estrutura composicional e estilo ${ }^{6}$.

Acreditando na relevância da aplicação dessa proposta, para a qual contamos com trinta aulas de cinquenta minutos, apresentamos seus objetivos e, logo em seguida, sua configuração:

1. Utilizar a oralidade na sala de aula, especialmente em momentos de apresentação de seminários;

2. Pesquisar sobre um tema de interesse dos alunos;

3. (Re)conhecer o gênero seminário como gênero expositivo oral;

4. Identificar o conteúdo temático, o estilo e a estrutura composicional do gênero seminário;

5. Desenvolver competências comunicativas necessárias à apropriação do gênero seminário;

6. Aprender sobre os gêneros orais entrevista e debate para a preparação e apresentação do seminário;

7. Utilizar gêneros orais (entrevista e debate) para preparar o gênero seminário;

8. Socializar seus conhecimentos aprendidos sobre o gênero seminário com os demais alunos dos $9^{\circ}$ anos.

Primeira etapa: situação inicial (tempo estimado: duas aulas): esta etapa foi necessária para a apresentação da proposta didática aos alunos e para começar o processo de ensino-aprendizagem do gênero seminário. Tivemos, na sala de aula, uma conversa com os alunos, objetivando apresentar nossa proposta de intervenção com o gênero oral seminário, que será desenvolvido ao longo de uma proposta didática. Para isso, fizemos uma aula dialogada com os alunos com perguntas sobre o gênero seminário, seu ambiente de produção e suas funções comunicativas. Levantamos conhecimentos prévios

${ }^{6} \mathrm{As}$ atividades referentes a esses conteúdos estão distribuídas em diferentes módulos da proposta. 
dos alunos a respeito do que vem a ser um seminário e mostramos o vídeo com exemplo de uma apresentação de seminário feito em sala de aula por alunos do Ensino Fundamental (Disponivel em $<$ https://www.youtube.com/watch?v=kJtK-mG3vR0>. Acesso em: 10 nov. 2016).

\section{Segunda etapa: seminário diagnóstico (tempo estimado: quatro aulas):} foram usadas aulas para preparação e apresentação de um seminário diagnóstico de um tema proposto pela escola no bimestre, sem nenhuma orientação por parte do professor. Com esta etapa, objetivávamos estabelecer um primeiro contato com os alunos, enquanto locutores do gênero, com o seminário e diagnosticamos as dificuldades dos alunos em relação à produção desse gênero.

Solicitamos que os alunos produzissem o gênero oral seminário; apresentamos nossos critérios de avaliação da oralidade (competência verbal, competência para-verbal e não verbal), conforme Monteiro (2013), e observamos a competência comunicativa do aluno, avaliando sua comunicação verbal pelo conhecimento do tema, vocabulário e coerência discursiva; a comunicação para-verbal pela expressividade, entonação, tom de voz e a comunicação não verbal, pelo seu olhar, gestos e postura corporal por meio do quadro reproduzido a seguir.

\section{Quadro 01 - avaliação de competências comunicativas orais}

\begin{tabular}{|l|lr|l|l|}
\hline Critérios & $\begin{array}{l}\text { MB } \\
\text { bom) } \\
\text { pontos) }\end{array}$ & $\begin{array}{r}\text { (8-10 } \\
\text { (muito }\end{array}$ & $\begin{array}{l}\text { B (bom) } \\
\text { (6-8 pontos) }\end{array}$ & $\begin{array}{l}\text { (abaixo de 6 } \\
\text { pontos) }\end{array}$ \\
\hline Postura corporal & & & \\
\hline $\begin{array}{l}\text { Entonação/ritmo } \\
\text { /tom de } \\
\text { voz/olhar }\end{array}$ & & & \\
\hline Participação nos & & & \\
\hline
\end{tabular}




\begin{tabular}{|l|l|l|l|}
\hline $\begin{array}{l}\text { turnos / argument } \\
\text { ação }\end{array}$ & & & \\
\hline Polidez verbal & & & \\
\hline $\begin{array}{l}\text { Conhecimento do } \\
\text { tema }\end{array}$ & & & \\
\hline $\begin{array}{l}\text { Comunicação } \\
\text { para- verbal }\end{array}$ & & & \\
\hline $\begin{array}{l}\text { Comunicação não } \\
\text { verbal }\end{array}$ & & & \\
\hline
\end{tabular}

\section{Observações:}

Fonte: elaborado pelas autoras, com base em Monteiro (2013).

Terceira Etapa - Módulos: informamos aos alunos que o desenvolvimento das atividades desta etapa objetivava diminuir os problemas encontrados na apresentação do seminário diagnóstico e, portanto, de diminuir as dificuldades dos alunos, mais especificamente quanto ao trabalho com o conteúdo temático, estilo e estrutura composicional do gênero seminário. Além disso, esta etapa auxiliou o trabalho do professor com o gênero.

Módulo I (tempo estimado: doze aulas): destinamos as três primeiras aulas deste módulo para o tratamento de aspectos e questões relativas ao uso dos gêneros debate e entrevista, gêneros orais que auxiliaram na preparação do seminário. Entendemos que esse diálogo com outros gêneros orais ajudou no planejamento e levantamento de dados sobre o tema proposto. O gênero debate foi ensinado aos alunos, para que eles debatessem com seu grupo do seminário sobre o tema proposto no seminário e para que dividissem suas tarefas e ações durante a sua apresentação (planejamento do seminário) e a entrevista oral foi ensinada para que os alunos entrevistem pessoas dentro e fora da escola (os alunos escolherão as pessoas que vão entrevistar) para aquisição de conhecimento sobre seu tema que auxiliará na produção do seminário (levantamento de dados). Foram 
realizadas aulas expositivas, seis atividades entre produção de debate e entrevista na constituição deste módulo e a visualização de vídeos para observar os modelos didáticos e a prática de oralidade em ambos os gêneros propostos.

Módulo II - Características do gênero seminário: estilo, estrutura constitucional, temática: (tempo estimado: seis aulas): neste momento, trabalhamos com o registro formal da língua, técnicas de falar em público, organização de sua fala, retextualização do texto escrito para o texto falado, elementos constitutivos do gênero seminário com relação ao conteúdo temático (abordagem do tema com especialistas durante o seminário), estrutura composicional (introdução, desenvolvimento e conclusão do seminário) e estilo (organização da fala dos apresentadores, registro formal da lingua, gestos, postura corporal, entonação); além de destacar que existe a preparação do seminário, apresentação e a finalização do mesmo. Foram realizadas quatro atividades para que os alunos produzissem elementos constitutivos do gênero seminário (estilo, estrutura composicional e temática). Além de aulas expositivas e visualização de vídeos para observação de modelos didáticos do gênero.

\section{Módulo III - Planejamento do seminário (tempo estimulado: duas aulas):} após as aulas sobre as características e os elementos constitutivos do seminário, os alunos produziram novamente, para ser exposto aos demais colegas dos outros $9^{\circ}$ anos, outro seminário, de acordo com o mesmo subtema do seminário diagnóstico. Assim como foi feito no seminário diagnóstico, os alunos tiveram um momento em sala para planejar e discutir as ideias pesquisadas anteriormente em outras atividades sobre o subtema proposto (utilizando informações e o conhecimento/prática de gêneros orais e escrito com a entrevista e debate) e rever seu roteiro de apresentação também feito anteriormente na atividade de produção do debate e usar as informações coletadas nas entrevistas realizadas. 


\section{Produção final: seminário final (tempo estimado: quatro aulas consecutivas):} esta etapa consistiu na verificação da aprendizagem no que diz respeito à apropriação e ao domínio do gênero seminário. Neste momento, os alunos apresentaram um seminário aos demais colegas dos $9^{\circ}$ anos da escola. Para isso, foi escolhido um local que continha cadeiras, materiais tecnológicos e suporte para que os alunos apresentassem o seminário. Foi definido um horário e feito um convite escrito aos alunos do $9^{\circ}$ ano e professores para assistirem ao seminário.

Os alunos-ouvintes, por sua vez, tiveram a oportunidade, sob nossa mediação, de aprender o gênero seminário por meio de entrevistas que farão após o seminário, com perguntas espontâneas sobre como fazer um seminário e receberão as respostas por meio de comentários dos alunos que estiverem apresentando.

Objetivamos, nesta etapa da proposta didática, promover uma interação e um processo de ensino-aprendizagem entre os alunos que aprenderam o gênero seminário e os demais alunos de outras turmas que ainda não tiveram oportunidade de ter acesso a esse gênero, nas aulas de Lingua Portuguesa.

Concluídas todas as etapas da aplicação da proposta, podemos concluir que a realização deste trabalho proporcionou ricos momentos de prática da oralidade, uma vez que os alunos envolvidos com a pesquisa tiveram oportunidade de produzir conhecimento aproveitado tanto por eles mesmos quanto pelos colegas de outras turmas. Temos a certeza de que esse conhecimento contribuirá para que eles sejam capazes de produzir outros seminários, que certamente serão solicitados em diversos outros contextos comunicativos.

Finalmente, esperamos que essa proposta possa contribuir para que tanto os alunos quanto os professores encontrem caminhos mais produtivos para trabalharem com o gênero seminário. Esperamos, também, que a partir dela, o professor tenha mais facilidade em trabalhar a oralidade, usando inclusive outros gêneros orais como o debate e a entrevista em suas aulas. 


\section{Considerações Finais}

Entendemos, tal qual Marcuschi (2008), que se deve estudar uma língua por meio de textos, em um contexto de compreensão, produção e análises textuais. Esse contexto favorece, portanto, o trabalho com os diversos e variados gêneros orais e escritos. Quando observamos, entretanto, como se dá o ensino de Língua Portuguesa em muitas escolas brasileiras, notamos que os professores tendem a priorizar a prática de gêneros escritos e que quando se fala em prática de oralidade e produção de gêneros orais há dificuldades de ensino.

Essa realidade nos leva a pensar que a prática da oralidade, principalmente nas aulas de Lingua Portuguesa, tem sido pouco trabalhada pelos professores, o que pode ocorrer por diversos motivos: i) talvez pela valorização da escrita, que representa no ideário docente a modalidade de língua "por excelência"; ii) por timidez dos alunos; iii) falta de conhecimento do professor sobre a oralidade como prática social; iv) falta de opções de recursos didáticos e discussões sobre oralidade e ensino. Porém, observamos que a oralidade é importante dentro e fora do contexto escolar, especialmente em situações formais, uma vez que, por meio dela, o aluno será exposto a diversas situações de uso da língua, o que exigirá dele o domínio tanto da modalidade falada como dos gêneros orais.

Em relação ao ensino de gêneros orais, entendemos que compete ao professor ensinar ao aluno o contexto social do gênero seminário, sua estrutura, linguagem, objetivos e promover uma reflexão sobre ele, bem como mostrar situações reais que "exigirão" o domínio desse gênero. O trabalho com o seminário poderá, então, ser interessante, uma vez que ele representa uma situação real de uso da oralidade e não uma simulação de uma realidade produzida pelo aluno, como acontece na produção de diversos gêneros trabalhados durante a rotina escolar.

A partir da aplicação da proposta didática do gênero seminário com uma turma de $9^{\circ}$ ano, percebemos que ela favoreceu a aproximação e 
interação entre os próprios alunos e o professor, dando a chance a todos os alunos de aprenderem, com seus colegas, como produzir o gênero seminário e principalmente a oportunidade de uso efetivo da oralidade em sala de aula. Além disso, podemos dizer que a proposta apresentada poderá oferecer possibilidades a outros professores e alunos de Lingua Portuguesa de ensinar e aprender o gênero seminário por meio de outros gêneros orais.

\section{Referências}

ANTUNES, I. Aula de Português: encontro e interação. Rio de Janeiro: Parábola, 2003.

BAKHTIN, M. M.; VOLOSCHINOV, V. N. Marxismo e Filosofia da Linguagem: problemas fundamentais do método sociológico na ciência da linguagem. 12 ed. São Paulo: Hucitec, 1997.

BAKHTIN, M. M.; VOLOSCHINOV, V. N. Estética da criação verbal. 6. ed. São Paulo: Martins Fontes, 1997.

BRAIT, B.; ROJO, R. Organização de seminário ou exposição oral. In: Gêneros: artimanhas do texto e do discurso. São Paulo: Escolas Associadas. 2002. (Coleção Linguagens e Códigos).

BRASIL. Secretaria de Educação Fundamental. Parâmetros curriculares nacionais: introdução aos parâmetros curriculares nacionais / Secretaria de Educação Fundamental. Brasília: MEC/SEF, 1997.

Parâmetros Curriculares Nacionais: primeiro e segundo do ensino fundamental: Língua Portuguesa/ SEF, Brasília: MEC/SEF, 1998.

CAVALCANTE, M. C. B; MELO. Oralidade no ensino médio: em busca de uma prática. In: BUNZEN, C; MENDONÇA, M. (Org.). Português no ensino médio e formação do professor. São Paulo: Parábola, 2006, p. 181-198.

DOLZ, J.; NOVERRAZ, M.; SCHNEUWLY, B. Sequências didáticas para o oral e a escrita: apresentação de um procedimento. In: SCHNEUWLY, B.; DOLZ, J. Gêneros orais e escritos na escola. Tradução e organização Roxane Rojo e Glaís Sales Cordeiro. Campinas, SP: Mercado das Letras, 2004.

DOLZ, J.; B. PIETRO E SCHNEUWLY, J. A exposição oral- In: DOLZ, J. e SCHNEUWLY, B. Gêneros orais e escritos na escola. Campinas, São Paulo: Mercado das Letras, 2004.

DOLZ, J.; SCHNEUWLY, B.; HALLER, S. O oral como texto: como construir um objeto de ensino. In: SCHNEUWLY, B.; DOLZ, J. Gêneros orais e escritos na escola. Tradução e organização de Roxane Rojo e Glaís Sales Cordeiro. Campinas: Mercado das Letras, 2004, p. 125-155.

FREITAS, P. R. de. Produção oral no seminário: possiveis apropriações em uma prática de ensino. Campinas, SP: Unicamp, 2006.

GERALDI, J. W. Concepções de linguagem e ensino de português. In: GERALDI, J. W. (Org.). O texto na sala de aula; leitura e produção. Cascavel: Assoeste, 1984. p. 41-49 
GOULART, C. As práticas orais na escola: o seminário como objeto de ensino. Dissertação (Mestrado em Linguística Aplicada) - Instituto de Estudos da Linguagem, Universidade Estadual de Campinas, Campinas. 2005.

MARCUSCHI, L. A. Produção textual, análise de gêneros e compreensão. São Paulo: Parábola Editorial, 2008.

Da fala para a escrita: atividades de retextualização. 10.ed. São Paulo: Cortez, 2010.

VIEIRA, A. R. F. O seminário: um evento de letramento escolar. Recife: 2005. MONTEIRO, C. et al. Avaliação da competência comunicativa oral no Ensino Básico: um estudo exploratório. Revista Portuguesa de Educação, 2013.

SCHNEUWLY, B.; DOLZ, J. Gêneros orais e escritos na escola. Trad. Roxane Rojo e Glaís Sales Cordeiro. São Paulo: Mercado das Letras, 2004. 